\title{
Form and meaning in cognitive morphology
}

\section{Henryk Kardela}

University of Maria Skłodowska-Curie, Lublin, Poland

\begin{abstract}
The paper applies Ronald Langacker's conception of Baseline/Elaboration (B/Eorganisation) to derivative morphology. It is claimed that the $\mathrm{B} / \mathrm{E}$ approach to linguistic structure, according to which "structure and function are indissociable like the two sides of a coin" (Langacker, 2016, p. 24), offers a viable, theoretically interesting account of the dynamic relationship between the form and meaning of morphological units.
\end{abstract}

Key words: Cognitive Grammar, B/E organisation, semasiology, onomasiology

\section{Introduction}

Pointing to the Saussurean roots of cognitive grammar, John Taylor (2002, p. 39) observes that

[...] cognitive grammar is driven by a view of language that arguably does have much in common with certain aspects of Saussure's thought. I refer to Saussure's insistence that the basic object of linguistic enquiry is the linguistic sign, and to his characterization of a language as a system of signs. Langacker has explicitly acknowledged the affinity with the Cognitive Grammar approach. ${ }^{1}$

The "affinity with the Cognitive Grammar approach" becomes clear when one takes into consideration Ronald Langacker's analysis of the relations obtaining between the semantic pole, [S] (which corresponds to Saussure's signified), and

${ }^{1}$ Language, Langacker (1987, p. 11) notes, "is symbolic in nature. It makes available for the speaker - for either personal or communicative use - an open-ended set of linguistic signs or expressions, each of which associates a semantic representation of some kind with a phonological representation. I therefore embrace the spirit of classic Saussurean diagrams [...], with the understanding that explicit, substantive characterization is required for the elements they depict." 
the phonological pole, [p] (which corresponds to the Saussurean signifier), of a composite linguistic expression such as, for instance, tea bag (cf. Langacker's, 2008, p. 162 analysis of jar lid; see also Kardela, 2019, for discussion):

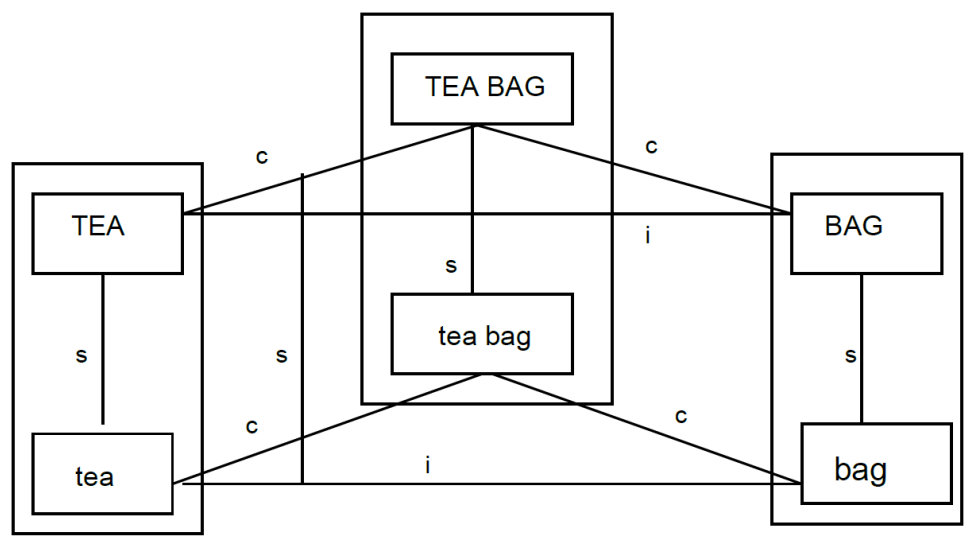

Fig. 1. The relations between the phonological pole, [p], and the semantic pole, [S], of a linguistic expression, where $c=$ composition; $\mathrm{i}=$ integration, $s=$ symbolization

Langacker's reformulation of the linguistic sign, which serves as the basis for the characterization of linguistic units such as tea bag, departs from Saussure's conception of the sign in two important respects: (i) it offers a "seamless" account of the signified-signifier relation, i.e. the relation between the "S"-pole and the "p"-pole of a linguistic expression and (ii) it allows us to view the signifiersignified relation in "dynamic" terms by treating the meaning of linguistic units as emergent structures. The paper accounts for the internal dynamicity of linguistic units in terms of two closely interrelated concepts: baseline and elaboration (B/E elaboration) as envisaged in Langacker (2016). The paper is divided into several sections.

In Section 2, we offer a discussion of asymmetries between the phonological and semantic poles of linguistic expressions, which, in our view, can be adequately accounted for by Langacker's model of grammar. Section 3 briefly sketches the structure-function relation obtaining between the two poles of linguistic expressions as envisaged in Langacker (2016). The discussion of $\mathrm{B} / \mathrm{E}$ organization prepares the grounds for recasting in Section 4 , in terms of $\mathrm{B} / \mathrm{E}$, the $\mathrm{A}$ (utonomy)/D(ependence) asymmetry in morphology as discussed in Tuggy (1992) and Kardela (2000). 


\section{The lexicon-grammar continuum and meaning-form asymmetries}

In cognitive linguistics, lexicon and grammar form a continuum of linguistic units. "Where does lexicon stop and grammar begin?," Langacker (2008) asks. And he answers (p. 22):

The point $[\ldots]$ is that there is no particular place. But this is not to say that no distinction can be drawn. The key parameter is specificity. To the extent that symbolic assemblies are specific, they would tend to be regarded as lexical, both traditionally and in CG. To the extent that they are schematic, they would generally be considered grammatical. Thus lexicon can be characterized as residing in fairly specific symbolic assemblies, and grammar in more schematic ones.

That lexicon and grammar form a gradation of lexical units rather than being clearly separable follows from an extendable nature of schematic units. Thus, as noted by Langacker, there exist a great number of schematic expressions which "conform to the stereotype of neither lexicon nor grammar" (Langacker, 2008: 20). Examples are units such as X crane X+POSS neck (John craned his neck), $\mathrm{V}_{\mathrm{s}} \mathrm{X}$ in the $\mathrm{Nb}$ (John slapped Greg in the face), and a $\mathrm{N}_{1}+$ less $\mathrm{N}_{2}$ (a moonless night). Expressions of this kind, Langacker observes (p. 20),

are non-stereotypical for grammar by virtue of containing specific lexical elements. They are non-stereotypical for lexicon because of their partial schematicity. They are not themselves full-fledged expressions but patterns abstracted from them and potentially used in forming new ones. To this extent they are grammar-like, since grammar by definition comprises the patterns used in forming complex expressions. In an effort to preserve the standard dichotomy, $\mathrm{X}$ crane $\mathrm{X}+\mathrm{POSS}$ neck could be assigned to the lexicon, as it contains the indisputably "lexical" elements crane and neck, whereas a N1+less N2 might be considered grammatical because its only specific components ( $a$ and -less) are "grammatical markers". This will not solve the problem, however. Apart from being aprioristic, it leaves us with an arbitrary choice in cases like $\mathrm{Vs} \mathrm{X}$ in the $\mathrm{Nb}$, where $\mathrm{Vs}$ and $\mathrm{Nb}$ are intermediate in specificity (Vs designating a certain type of action, and $\mathrm{Nb}$ a body part).

${ }^{2}$ For a discussion of the "continuum of language areas," see, for example, Dirven and Verspoor (2004, pp. 69-70). 
In conclusion, Langacker observes (p. 20)

What the linguistic data seems to be trying to tell us is that lexicon and grammar form a gradation instead of being sharply dichotomous. That, of course, is a central claim of CG, which further contends that the full gradation reduces to assemblies of symbolic structures.

It should be observed that many symbolic expressions and especially idiomatic expressions such as, say, crane one's neck or kick the bucket exhibit an asymmetry in constituency between their phonological and semantic poles. Thus crane one's neck means 'stretch one's neck in a particular direction in order to see something better' and kick the bucket means 'to die'. The same is true in the case of "pure" morphological formations. Thus, whereas in the case of regular composite forms such as tables, we have a one-to-one correspondence between the constituency at the semantic and phonological poles (cf. 1a), in the case of irregular formations such as feet (1b) or caught (1c), blends like motel (1d) and acronyms, no one-toone correspondence holds (cf. Kardela 2019): ${ }^{3}$

(1) a. [[TABLE/table $]-[\mathrm{PL} / \mathrm{s}]]$

b. $[$ FOOT/foot $] \sim[$ FEET/feet $] \mathrm{PL}$

c. $[\mathrm{CATCH} /$ catch $]] \sim[\mathrm{CAUGHT} /$ caught $]$ PRET

d. [[MOTOR] - [HOTEL]/motel]]

e. [[NORTH ATLANTIC TREATY ORGANIZATION]/[nato]]

The asymmetries in the constituency between the semantic and phonological poles of linguistic expressions are of direct theoretical interest to any cognitive account of linguistic structure which takes seriously the "lexicon-grammar continuum" thesis. For, seen in this light, the idea of morphology based on the concept of a "morpheme", traditionally defined as "the minimal unit of meaning" (see, for example, Fromkin et al., 2014, Chap. 3), must be revised. Revision is also necessary of any traditional views of morphology which divide the entire discipline into several subparts: "derivational morphology," "inflectional morphology," "exceptions and suppletions," and the so-called "other morphological processes," including back formations, compounds, blends, initialisms and acronyms.

In what follows we propose to look at morphological structure in terms of "dynamic associations" which, as we claim, following Langacker (2016), hold

${ }^{3}$ Capital letters stand for the semantic poles of the linguistic expressions, whereas small letters, for their phonological poles. 
between the phonological and semantic poles of linguistic expressions. We will thus enquire into the nature of the relationship between structure (form) and function (meaning) as discussed in Langacker (2016). ${ }^{4}$

\section{Structure and function in cognitive grammar}

Commenting on the nature of the structure-function relations obtaining in a linguistic unit, Langacker (2016, p. 16) notes that

[s]tructure is often identified with grammar, and function with meaning. Or structure with lexicon, morphology, syntax, and phonology, and function with things like semantics, pragmatics and discourse functions. This is really a kind of disguised metaphor. It's a manifestation of the substance/activity distinction which I think is ultimately wrong.

For Langacker, the substance/activity distinction is a false dichotomy, given that the "formal" elements are substantive only metaphorically [and because] [p]honological, lexical, and grammatical structures consist in patterns of processing activity, just as meanings do (Langacker, 2016, p. 17).

Because, as Langacker notes, the patterns of processing activity apply at all levels of conceptual organization, where "a structure of any size consists in organized activity," the structure vs. function is "just a matter of perspective" (p. 17).

Yet, assuming, as Langacker does, that conceptual organization is an organized activity and is a matter of perspective, the question arises how can concepts, defined in Taylor (2002, p. 43) as "the principles of categorization", structure for us a clear and coherent picture of experienced reality? Clearly, some sort of stability is to be expected in this regard. Langacker (2016, p. 17) comments:

A pattern of activity can be stable in the sense of being "entrenched" and able to recur: an established processing routine (a unit, in CG terms) [which] to some extent $[\ldots]$ decomposes into subpatterns - parts within the whole.

These subpatterns, Langacker observes (p. 17), "are connected in various ways [by] association, temporal sequencing, partial overlap." As a result, the structural configuration of an expression emerges. When we attempt to describe structures involved in it p. 17),

${ }^{4}$ See also Kardela (2019) for an extensive discussion of Langacker's views of the substance/ form relationship based and his theory of $\mathrm{B} / \mathrm{E}$ elaboration. 
we are implicitly describing [their] functions: we are describing lower-level structures, and we're describing how they map onto aspects of higher-level structures, and this amounts to characterizing the functions.

But what exactly is structure? Structure, Langacker notes, is a configuration in which entities (or elements) are connected via three types of connections, including (p. 20)

(i) overlap in the activity comprising the connected elements;

(ii) association, such that one structure tends to activate another;

(iii) operations (e.g. comparison, categorization, assessment of relative position in some field).

It should be stressed that in Langacker's theory, the same elements can be connected in many different ways; they produce structures that can be further enriched with, or augmented by (Langacker's term), elements and/or connections. For Langacker, connection "produces a new entity which represent[s] a higherlevel of organization," where (p. 21)

(i) the higher-level entity has emergent properties, minimally including the nature of the connections and any adjustments the component elements undergo;

(ii) a component of a higher-level entity may participate individually in further connections;

(iii) a higher level entity (being a structure in its own right) can also participate as a whole in further connections. This is so when the connections depend on emergent properties;'

(iv) when this happens at successive levels, the result is hierarchy.

When a higher-order entity, i.e. a set of connected elements, transfers its potential to a higher-level structure and starts functioning in this structure, a grouping emerges. The process of the emergence of grouping can be presented as follows (p. 23):

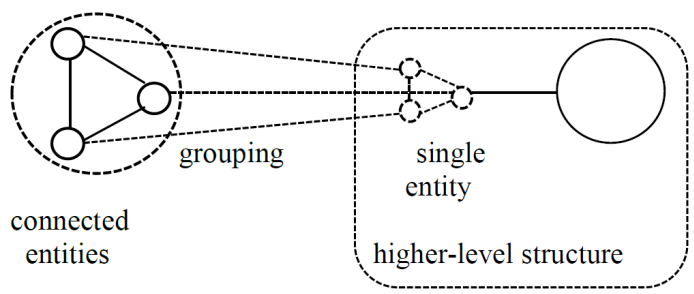

Fig. 2. The process of grouping 
We have already quoted Langacker as saying that "structure vs. function is [...] a matter of perspective." Functions, Langacker further observes, "require structures for their implementation," that is, "a vast assembly of semantic and phonological structures connected by relations of symbolization, categorization, and composition." Structure vs. function is, to use his formulation, "a shorthand for symbolic structure/function vs. semantic structure/function." Seen in this light, the semantic pole of an assembly (i.e. an assembly's semantic structure/ function) is part of its symbolic structure/function. If so, all asymmetries involving constituency can now be handled in a systematic way. Says Langacker (p. 27):

Consider $[\ldots]$ a noun phrase, or a nominal as I call it. People commonly believe that a nominal consists of a determiner plus a head noun, but obviously that doesn't work. There are all sorts of nominals that don't have a determiner or don't have a head noun. We have the package, which conforms to that pattern. Packages is a nominal but there is no determiner. Or, those wrapped in newspaper is a nominal, but it has no head noun. There is nothing that all nominal structures share, unless you start arbitrarily putting in zero forms to make them look like they have those other elements. The only common feature is the semantic function of nominal reference.

In conclusion (p. 28), Langacker observes:

Semantic function is essential for grammar. It is more fundamental and more consistent than things like grammatical constituency.

If semantic function is more important than grammatical constituency, then an obvious question to ask is how one can distinguish between, say, agentive -er derivatives and instrumental -er derivatives in English, i.e. between derivatives such as printer 'a person who prints' and printer 'a machine that prints'? One can do this by invoking the notion of system, which is characterized by Langacker (p. 28) as "a set of elements that fulfill a certain function [...]." This set of elements, called by Langacker exponents or members of the system, are mutually exclusive; they are, as Langacker puts it, "in opposition to one another in neural terms [and being] connected by inhibitory (rather than excitatory) links" (p. 28). The exponents of a system, Langacker observes, "are partially defined by what they are not - their place in a system of opposition. [Thus] in the system [i a u], [i] is partly defined by not being [a] or [u]." Exponents of a system are therefore "contrasting instantiations of the same schema." (p. 28) In the case of the $-e r$ suffix, the agentive and instrumental suffixes will thus be treated as "contrasting instantiations" of the -er suffix schema, hence serving the same function, with the links between them forming a relationship of categorization. The function/ 
schema-related categorizing relationship between the three senses of the $-e r$ suffix can be presented as follows (er-AG = printer (human); er-INS = printer (machine); er-LOC = container; based on Langacker's diagrams, p. 29; cf. Kardela, 2019):

a.

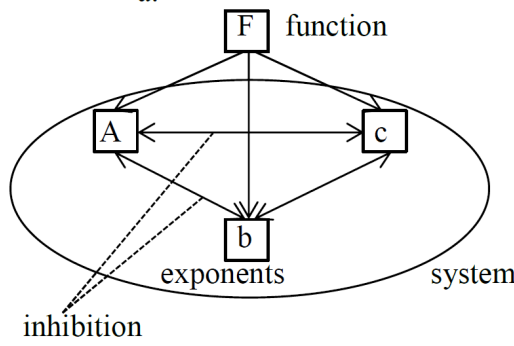

b.

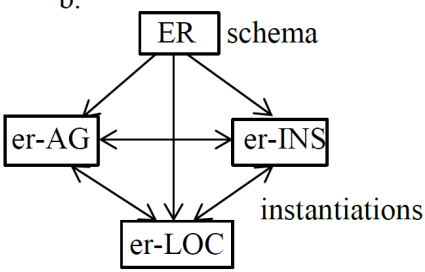

Fig. 3. The schema/function based categorizing relationship between the various senses of $-e r$

Now, in order to account, in terms of a Cognitive Grammar approach, for the asymmetries shown in (1a-e), we have to introduce two distinct yet interconnected notions: baseline and elaboration. Below we give the original formulations of these notions (p. 36):

(i) The notions baseline and elaboration pertain to asymmetries observable in any facet of language structure or its conceptual and phonological basis.

(ii) The baseline (B) is already established, in place, or under control. Its elaboration (E) by augmentation, adaptation, or further processing - produces a structure that may itself function as B at another stage or level of organization.

(iii) $\mathrm{B} / \mathrm{E}$ organization has thus a temporal aspect, $\mathrm{B}$ in some sense being prior to $\mathrm{E}$.

(iv) However, this happens on very different time scales and may just be a matter of inherent organization (or 'logical necessity'). ${ }^{5}$

${ }^{5} \mathrm{~B} / \mathrm{E}$ organization involves a variety of phenomena, including

(i) the conception of norm, in which case, as Langacker (2016, p. 37) notes, "any kind of norm is a baseline [and] departures from it are elaborations;"

(ii) linguistic change, where "the current state of a language is a baseline [and] change constitutes elaboration;"

(iii) categorization, in which case "the categorizing unit is a baseline used to apprehend the target, which departs from it in terms of greater specificity or a conflict in specification;"

(iv) the conception of prototype involving a complex category, where "prototype is the baseline from which other variants develop by extension, specialization, or schematization;"

(v) a number of asymmetries including concrete/abstract, or physical/mental, where "the first element provid[es] the basis for apprehending the second." (p. 37). 
For our purposes, it is important to bear in mind that $\mathrm{B} / \mathrm{E}$ organization includes what Langacker calls A/D asymmetry (autonomy-dependence asymmetry). A/D Asymmetry is defined as follows (Langacker, 2016, p. 39; cf. also Langacker, 1987, p. 300):

(i) In $\mathrm{A} / \mathrm{D}$ organization, $\mathrm{A}$ is autonomous - with the potential to be manifested independently - and D is dependent on $\mathrm{A}$, which it requires for its full manifestation.

(ii) Conceptually, a thing tends to be autonomous, whereas a relationship - consisting in connections - is dependent on its participants (the entities connected).

(iii) Phonologically, vowels are autonomous and consonants dependent on them, consisting in modulation of the sonority they provide.

(iv) Likewise, the manifestation of prosodic features - like accent or tone - depends on segmental (primarily vocalic) content, with which they temporarily coincide.

The idea of A/D asymmetry has also been used to account for the stem-affix combination in morphology (cf. Tuggy, 1992; Kardela, 2000). In what follows, we take a fresh look at A/D asymmetry, recasting it in terms of baseline and elaboration.

\section{B/E asymmetry in morphology}

On the basis of traditional morphological analysis, David Tuggy, ${ }^{6}$ offers an A/D Asymmetry - based account of stem-affix combinations. For a point of departure for his analysis, Tuggy takes Langacker's (1987, p. 300) definition of dependence, according to which "one structure, $\mathrm{D}$, is dependent on the other, $\mathrm{A}$, to the extent that A constitutes an elaboration of a salient substructure of D." Couched in these terms, the stem-affix relationship is said to involve the mutual elaboration of the stem's and affix's elaboration sites (e-sites)(cf. Kardela, 2000, p. 50; modified):

${ }^{6}$ According to traditional morphological analysis (Tuggy, 1992: 238),

(i) affixes are "bound morphemes" in the sense that they "they cannot be unattached," whereas stems are "free and can occur without any other morphemes attached," an affix "is intrinsically incomplete and needs a companion in order to be manifested linguistically;"

(ii) stems are "semantically heavier" in the sense that they "are often said to have lexical content;"

(iii) affixes are productive and "can attach to an unspecifiably large number of different stems," while stems are said to "permit a relatively small number of affix combinations to be use with them;"

(iv) stems have "greater phonological weight than affixes." 


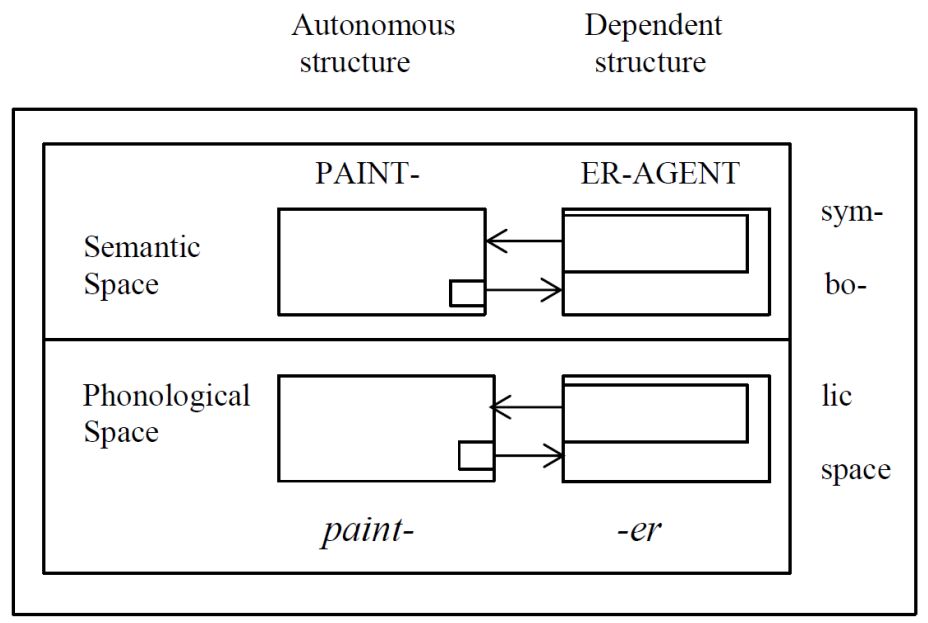

Fig. 4. The mutual elaborative relations between the stem and the affix

The diagram shows two linguistic units: a dependent structure, the suffix -er, and an autonomous unit, the stem paint-. In this configuration, the autonomous structure elaborates both the semantic and phonological poles of the dependent structure, and the other way round: the dependent structure elaborates the semantic and the phonological poles of the autonomous structure. Elaboration is marked by arrows; the smaller boxes within larger boxes stand for elaboration sites.

Note that the sizes of the elaboration sites differ: the stems' elaboration sites are larger than those of the affixes because the stem, in contrast to the affix, is the basic carrier of semantic content, hence its elaboration site is smaller than that of the affix. Put differently, because the suffix $-e r$, in order to be able to function in the composite structure [[PAINT/paint]-[ER/er]] must get more semantic and (morpho)phonological information relating to the affix-stem combinability than the stem, the size of its e-site must be larger than that of the stem's.

Still, having adopted Langacker's "form-function idissociablity thesis," we need an explicit characterization of the relations which hold between the two poles of expressions as presented in Fig. 1. It is precisely at this point that $\mathrm{B} / \mathrm{E}$ organization proves to be of great help.

First, we have to introduce, following Langacker, the conception of strata and the distinction between core and periphery layering. ${ }^{7}$ In Langacker's theory,

\footnotetext{
${ }^{7}$ According to Langacker (2016, p. 40),

When we talk about $\mathrm{B} / \mathrm{E}$ organization, there are always three elements involved: there is $\mathrm{B}$, the baseline; there is E, the elaborating structure; and there's BE, the combination or the result of that elaboration. These exhibit certain asymmetries: B is prior to E, B is typically more substantive
} 
$\mathrm{B} / \mathrm{E}$ organization involves what he calls layering - an arrangement, in terms of core and periphery - of strata, where "each stratum $\left(\mathrm{S}_{\mathrm{i}}\right)$ is a substrate for the next $(\mathrm{Si}+1)$, providing the basis for its emergence" and where "Si+1 elaborates $\mathrm{Si}_{\mathrm{i}}$ by invoking additional resources allowing a wider array of alternative" (p. 41). The layering of strata via the elaboration process can be presented as follows (Langacker, 2016, p. 45): ${ }^{8}$

a. Elaboration

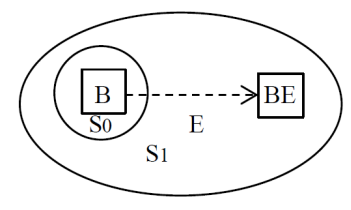

b. Alternative elaborations

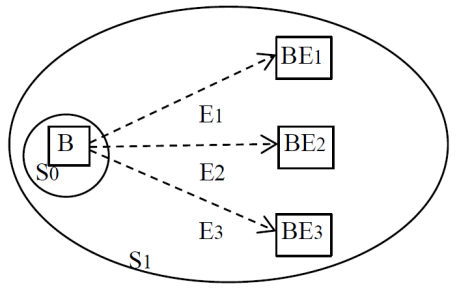

Fig. 5. Ways of elaborating a baseline

In view of the above, consider now the formation of the plural form cats as depicted in Fig. 6(a) and discussed in Langacker (2016, p. 54), and the formation of the irregular plural geese, given in Fig. 6(b):

(a)

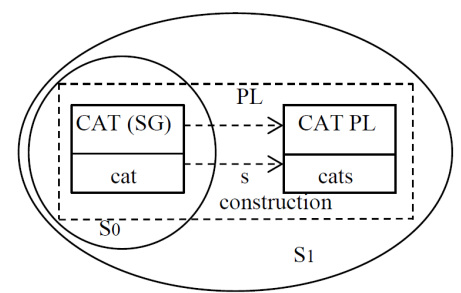

(b)

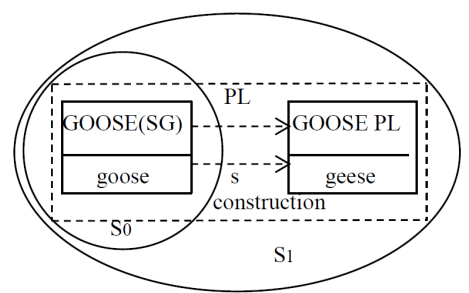

Fig. 6. The B/E organization of cats and geese

than $\mathrm{E}$, and $\mathrm{BE}$ is more complex than B. In (37)(f), for instance [see directly below - H. K.], the vowel [a] is the initial baseline; it's more substantive (sonorous) than the elaborating structure, [y], which is a glide. The result of the elaboration, [ay], is more complex than either of these individually. In view of these asymmetries, B/E organization represents a kind of layering, also describable in terms of core and periphery.

Fig. 37 (f) (Langacker, 2016, p. 40; adapted):

$$
\text { [a] } \stackrel{\mathrm{y}}{\rightarrow} \text { [ay] } \stackrel{1}{\rightarrow} \text { [ayl] } \stackrel{\mathrm{z}}{\rightarrow} \text { [aylz] }
$$

${ }^{8}$ In Fig. 5, only two ways of elaborating a baseline are shown; two other types: elaboration via chain of elaborations and dimensions of elaborations (alternate directionality of elaboration), are not discussed here. 
Note that under Langacker's definition of baseline and elaboration, the form cats in Fig. 6(a) conforms to the elaboration process shown in Fig. 5(a), where cat is the baseline (B), hence $\mathrm{S}_{0}$, and cats is the elaboration (BE), hence $\mathrm{S}_{1}$. In the case of geese, however, the situation is different. As before, the form goose in Fig. 6(b) is the baseline and geese is the elaboration, but in contrast to cats, geese is an alternative elaboration of goose, hence conforms to the representation shown in Fig. 6(b). Note also, that in contrast to cats, which is a prototypical (hence core) plural formation, geese is not; for, seen through the prism of Fig. 6(b), cats represents a BE1 formation, while geese, which a is non-prototypical plural formation, a BE2 composite structure.

We can now extend the conception of B/E organization to all morphological structure. In connection with this, let us distinguish between semasiological and onomasiological elaboration - E-Sem and E-Onom elaboration, respectively. ${ }^{9}$ E-Sem involves the semasiology-based B/E-organization of a linguistic unit's meaning/function, whereas E-Onom concerns the onomasiology-related B/Eorganization of a linguistic unit's semantics/function.

Thus, with regard to E-Sem, let us assume that the elaboration in this case involves what the cognitive literature terms as the network model of interrelated senses. A good illustration of this type of elaboration is the network model of the English suffix -er, discussed in Panther and Thornburg (2003: 297; also discussed in Kardela, 2019):

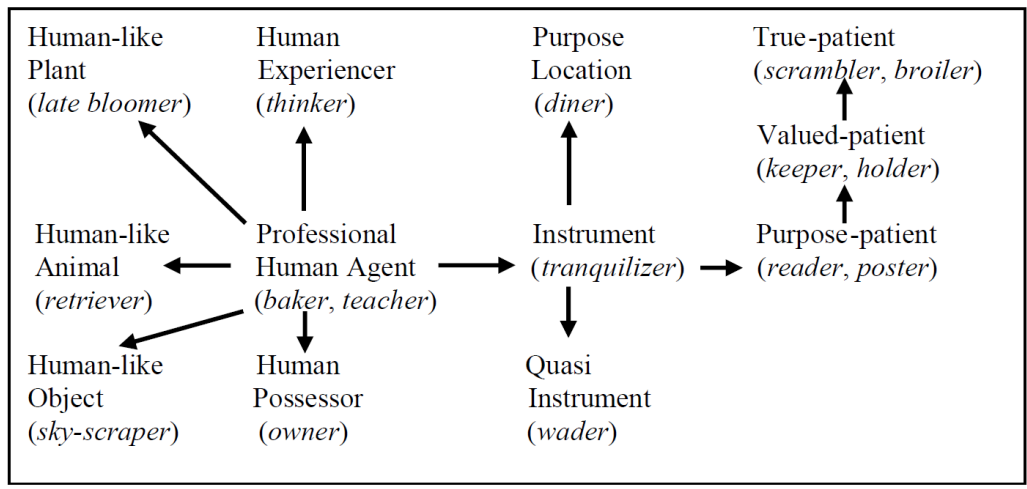

Fig. 7. The network of the interrelated senses of the suffix $-e r$.

${ }^{9}$ For the semasiology-onomasiology distinction, see, for example, Dirven and Verspoor (2004). For an onomasiological approach to morphology, see, among others, Dokulíl (1962/79), Grzegorczykowa and Szymanek (2001), Štekauer (2005) and Janda (2011). 
Turning to E-Onom elaboration, it should be noted that often in the onomasiological literature, a distinction is made between the derivational category and derivational type. In particular, as argued by Szymanek (1988), a given functionally established derivational category can subsume one or more derivational types, depending on how many co-functional formatives are used to realize this category. The category agent noun in English, for instance, looks as follows (Szymanek, 1988: 60; adapted):

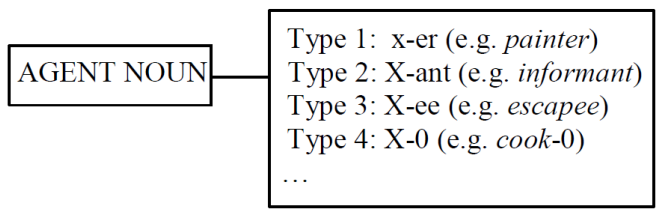

Fig. 8. The category agent noun and its derivational types

We can combine now Figs. 7 and 8 to arrive at a unified B/E account of the elaborative relations involving the suffix - er (cf. Kardela, 2019, p. 254):

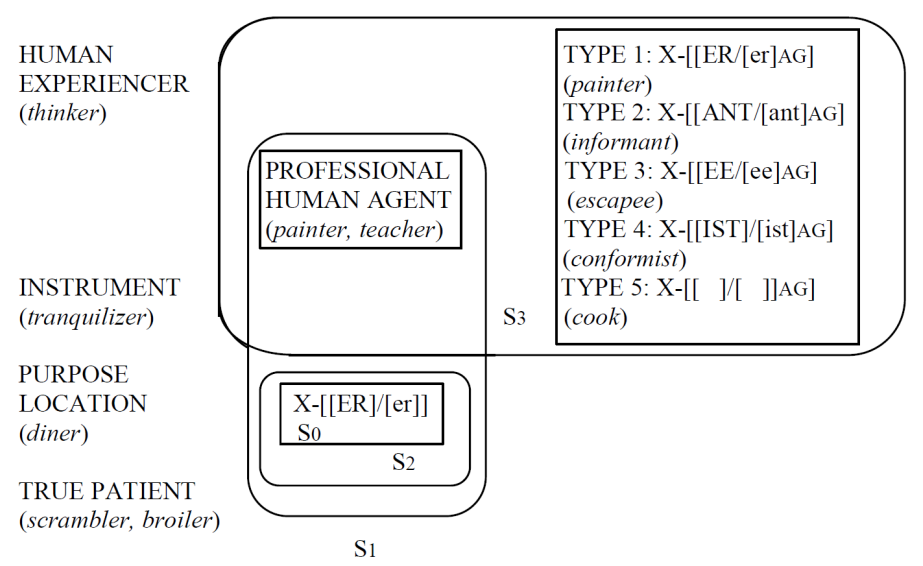

Fig. 9. E-Sem and E-Onom elaborations in morphology

Fig. 9 shows two kinds of relationships involving the English suffix [[ER]/ [er]]: (i) the E-Sem elaboration obtaining in the network of interrelated senses between the various semantic roles realized by $-e r$ (i.e. [PROFESSIONAL HUMAN AGENT], [HUMAN EXPERIENCER], [INSTRUMENT], etc.) and (ii) the E-Onom elaboration, which holds between the grammatical agentive category [PROFESSIONAL HUMAN AGENT], coded by $-e r$, and, co-functional with $-e r$, suffixes such as -ant, $-e e,-i s t,-0$. The meanings of the co-functional suffixes, which appear in the TYPE-box in capital letters, name the "agentive qualities" of agent nouns such as painter, informant, escapee, conformist, cook, etc. 


\section{Conclusion}

The cognitive grammar analysis of the -er suffix developed in this paper, while focusing on the conceptual, dynamic aspects of linguistic structure, takes into account the structural/generative view of word formation. This is understandable as no linguistic description develops in a theoretical vacuum. The problem is, however, what elements of the previous or competing theories can be incorporated into the new approach and how. After the period of the so-called Second Cognitive Revolution, ${ }^{10}$ after the total rejection by cognitivists of practically all mainstream/ generative grammar insights, the "voices of moderation" can now be heard in the Cognitivist camp to the effect that many solutions offered by main stream linguistics are valuable and deserve due attention. In this connection, it is instructive to quote from Onysko and Michel (2010, p. 5; also quoted in Kardela, 2019, p. 255):

These recent voices stressing the importance of investigating word formation in the light of cognitive processes can be interpreted from two general perspectives. First of all, they indicate that a structural approach to the architecture of words and a cognitive view are not incompatible. On the contrary, both perspectives try to work out regularities in language. What sets them apart is the basic vision of how language is encapsulated in the mind and the ensuing choice of terminology in the description of the processes. While a generativist, a structuralist. and by a similar token an optimality theoretic view [...] assume innate governing modules that formulate rules of language production and a separate word store as the mental lexicon, cognitive linguists tend to see structures and regularities emerging from a network of interconnections guided by general cognitive processes instantiated in language use. [...] cognitive linguistics takes a constructionist position on language, arguing in terms of lexical networks, emergent schemas, and associative patterns that create possibilities of expression, in contrast to a generativist-structuralist viewpoint of setting boundaries on language production via constraints operating on binary logic. In this way, cognitive linguistics concedes closely to the self-organizing nature of humans and their language whereas generativist-structuralist perspectives represent external boundaries as given in the institutionalized order of human interaction.

Asserting that "a structural approach to the architecture of words and a cognitive view are not incompatible" does not mean of course that the proposals advanced by structural/generative linguistics can be automatically incorporated into

${ }^{10}$ It is generally acknowledged now that while the First Cognitive Revolution started with Noam Chomsky's Generative Transformational Grammar, the linguistic models pursued within the general Cognitive paradigm, including Ronald Langacker's Cognitive Grammar, represent the Second Cognitive Revolution. 
cognitive analysis. The idea of $\mathrm{B} / \mathrm{E}$ organization which involves the layering of strata mechanism clearly precludes this possibility. As Figs. 2, 3, 5 and 9 show, the unit's phonological pole (Saussure's signifier) is, from the point of view of B/E organization, "immersed" in the "open-ended" semantic/conceptual structure (Saussure's signified) with no visible sense of semasiological or onomasiological direction of the signification process. Yet, to reiterate, many "traditional" solutions can be contemplated in the cognitive linguistics paradigm; the only problem is how to recast them in cognitive terms. This paper proposes a method for doing this.

\section{References}

Dirven, R., and Verspoor, M. (2004). Cognitive Exploration of Language and Linguistics. Amsterdam: John Benjamins.

Dokulíl, M. (1962/1979). Teoria derywacji [Theory of Derivation]. Wrocław: Ossolineum.

Fromkin, V., Rodman, R. and Hyams, N. (2014). Introduction to Language. $10^{\text {th }}$ Edition. Boston: Wadsworth.

Grzegorczykowa, R. \& Szymanek, B. (2001). Kategorie słowotwórcze w perspektywie kognitywnej [Word formation categories in cognitive linguistics]. In J. Bartmiński (ed.), Wspótczesny Język Polski, (pp. 469-484). Lublin: The Maria Curie-Skłodowska University Press.

Janda, L. (2011). Metonymy in word-formation. Cognitive Linguistics, 22(2), 359-392.

Kardela, H. 2000. Dimensions and Parameters in Grammar. Studies on A/D Asymmetries and Subjectivity Relations in Polish. Lublin: The Maria Curie-Skłodowska University Press.

Kardela, H. (2019). On the dynamic nature of cognitive morphology. In A. Bondaruk and K. Jaskuła (eds.), All Around the Word. Papers in Honour of Bogdan Szymanek on His 65 ${ }^{\text {th }}$ Birthday, (pp. 237-257). Lublin: Catholic University of Lublin Press.

Langacker, R. (1987). Foundations of Cognitive Grammar. Vol. 1. Theoretical Prerequisites. Stanford: Stanford University Press.

Langacker, R. (2008). Cognitive Grammar. A Basic Introduction. Oxford: Oxford University Press. Langacker, R. (2016). Nominal Structure in Cognitive Grammar. The Lublin Lectures. Lublin: The Maria Curie-Skłodowska University Press.

Onysko, A. \& Sascha, M. (2010). Introduction: Unravelling the Cognitive in Word Formation. In A. Onysko \& M. Sascha (eds.), Cognitive Perspectives on Word Formation, (pp. 1-25). Berlin: Mouton de Gruyter.

Panther, K., \& Thornburg, L. (2003). The Roles of Metaphor and Metonymy in -er Nominals. In R. Dirven and R. Pörings (eds.), Metaphor and Metonymy in Comparison and Contrast, (pp. 279-319). Berlin: Mouton de Gruyter.

Štekauer, P. (2005). Onomasiological Approach to Word Formation. In Handbook of Word Formation, 203-232. Dordrecht: Springer.

Szymanek, B. (1988). Categories and Categorization in Morphology. In P. Štekauer \& R. Lieber, (pp. 34-78). Lublin: Catholic University of Lublin Press.

Taylor, J. (2002). Cognitive Grammar. Oxford: Oxford University Press.

Tuggy, D. (2002). The Affix-stem distinction. A cognitive grammar analysis of data from Orizaba Nahuatl. Cognitive Linguistics, 3, 237-300. 